\title{
The effect of preceptorship on nurses' training and preparation with implications for Qatar: A literature review
}

\author{
Hajer Arbabi, Jessie Johnson, Daniel Forgrave \\ University of Calgary Qatar, Doha, Qatar
}

Received: November 6, 2017

Accepted: January 17, 2018

Online Published: February 1, 2018

DOI: $10.5430 /$ jnep.v8n7p44

URL: https://doi.org/10.5430/jnep.v8n7p44

\begin{abstract}
Background and objective: The Primary Health Care Corporation in Qatar was established in 2012 and is comprised of 23 Health Centers. One of its goals is to create excellence in its workforce. A preceptorship program needs to be initiated at the Primary Health Care Corporation to ensure a high level of training for its nurses. The purpose of these preceptorship programs is to ensure nurses are equipped to carry out Qatar's National Health Strategy and in doing so the Primary Health Care Corporation has this as its goal. This study amis to assess the effectiveness of preceptorship program models that can eventually be used for adoption as training programs for nurses in Health Centers in Qatar.

Methods: A literature review of twenty articles published between 2006 and 2017 that focused on different models of preceptorship programs was conducted. The Mixed Methods Appraisal Tool was used to assess the quality of these studies. The data was analyzed by categorizing the included articles in a matrix sheet based on study design.

Results and conclusions: Preceptorship programs are effective in four key areas: increasing nursing knowledge, supporting effective and safe care delivery by newly graduated nurses, increasing organizational support, and decreasing turnover rate and cost.
\end{abstract}

Key Words: Nurse, Preceptor, Preceptorship programs, Primary care

\section{INTRODUCTION}

The Primary Health Care Corporation (PHCC) was established in Qatar in 2012 and is now comprised of 23 Health Centers (HC). Health services at various clinics, including Maternal and Child Health clinics, Well Baby clinics, NonCommunicable Disease, Pre-Marital clinics, Smoking cessation, and Home Care. These services are offered across all Health Centers in Qatar. New nurses continually join the PHCC, including recent graduates and those who are students. These new nurses are supervised by preceptors. Preceptorship has been effective in enabling the transition of new nurses to nurses who are capable of providing safe and competent patient care, enhancing the qual-ity of care, and increasing the retention of newly graduated nurses. ${ }^{[1]}$ However, the preceptors at PHCC have no specific training, education, or preparation regarding how to deal with new or novice nurses. This sometimes leads to unsafe practices by the new nurses, which have resulted in high rates of medication errors and patient falls. This is further complicated as there are currently no guidelines for preceptorship at PHCC. This lack of guidelines means no structured preceptorship programs are available to train experienced nurses to become effective

*Correspondence: Hajer Arbabi; Email: hmarbabi@ucalgary.ca; Address: University of Calgary Qatar, Doha, Qatar. 
preceptors in order to support new nurses. These issues can only be addressed through a structured preceptorship model at PHCC.

Implementing a structured preceptorship model is relevant and significant to Qatar because it aligns with Qatar's National Health Strategy that aims to ensure professional education and development of nurses. These nurses have a vital role as the base of service and care in health care settings. Maintaining their performance and competence is very important to ensure better patient outcomes and safer environments. Organizational support is very significant in order to provide orientation and training to ensure that nurses are not overwhelmed by their responsibilities and complex patients, allowing them to focus on patient outcomes. Without this support, new nurses may leave nursing altogether. PHCC must develop strategies to support and retain new nurses with the aim of improving patient and organizational outcomes.

To date, numerous studies have been conducted to describe the impact and outcomes of different models of preceptorship for graduate nurses and students. Some studies on preceptorship most often attempt to clarify the effects of preceptorship on new nurses ${ }^{[2,3]}$ and approaches to increase retention rate. ${ }^{[4]} \mathrm{A}$ few qualitative studies have examined nurses' perceptions to identify their learning needs as a preceptor, ${ }^{[5,6]}$ while other studies examined preceptors and preceptees perceptions to facilitate preceptorship model implementation. ${ }^{[7,8]}$ However, limited studies have been done to explore the impact of preceptorship models on new nurses, preceptors, and entire organizations in Qatar or other greater gulf countries, including Bahrain, Iraq, Kuwait, Oman, Saudi Arabia, and the United Arab Emirates. The aim of this paper is to explore different models of preceptorship that are being employed in other countries and recommend one of them for adoption in Primary Health Care Centers in Qatar.

Within the context of nursing education, the preceptorship model is widely used in the health profession. ${ }^{[2,9]}$ Preceptorship is defined as an educational model which facilitates a skill and motivates new nurses to be role models. ${ }^{[10]}$ It is also defined as "a formal, one-to-one relationship of predetermined length, between experienced nurses (preceptor) and novice nurse (preceptee) designed to assist the novice nurse in successfully adjusting to and performing a new role". ${ }^{[11]}$

Novice nurses may include student nurses, new nurses, or experienced nurses moving to new health care settings. ${ }^{[1]}$ These novice nurses need to be supervised by preceptors at health care settings during the first three months and may extend to six months if needed. Nursing preceptorship was established in several areas, such as hospitals and medical agencies, in the mid-1970s. ${ }^{[12]}$ At that time, nursing schools and hospital settings were separate from each other. ${ }^{[13]}$ There was a need for more inclusive hospital orientation for new nurses who were entering clinical practice. ${ }^{[13]}$ New nurses were oriented only to the basic knowledge regarding hospitals, such as policy, procedure, and organizational culture. ${ }^{[13]}$ These new nurses were assigned to their units to become familiar with aspects of their new roles. The deficiency of structured orientation may have led to reality shock, burnout, reduced job satisfaction, and an increased turnover rate of new nurses. ${ }^{[13]}$

\section{Background}

There are several purposes for conducting preceptorship programs. The objective of preceptorship programs is to support nurses to become qualified preceptors after attending preceptorship programs. They facilitate cooperation between hospitals and universities. ${ }^{[14]}$

Preceptorship programs increase the number of trained preceptors. This will have a positive impact on the professional support for student nurses. ${ }^{[4]}$ These programs are important to prepare and retain safe, competent nurses. ${ }^{[15]}$ Such programs will facilitate the effective transition of new nurses to nurses who can provide safe and competent patient care. ${ }^{[1]}$

Preceptorship programs support student nurses' learning outcomes through (a) preparing preceptors for their role; (b) helping student nurses to not be overwhelmed and socializing them to their professional roles; (c) assisting student nurses to integrate knowledge and skills into the clinical practice; ${ }^{[16,17]}$ and (d) enabling a smoother transition to clinical practice for student nurses. ${ }^{[7]}$ Preparing student nurses for their professional role could be achieved through structured preceptorship educational programs. ${ }^{[18]}$

\section{METHOD}

The databases used for this literature review included $\mathrm{Cu}$ mulative Index to Nursing and Allied Health Literature CINAHL, Ovid: Psych info, Embase, ERIC, and Pub Med, MEDLINE. The key search terms used were preceptor*, Baccalaureate*, Graduate* Nurs*, Program, and Model*. The Boolean operators AND and OR were used. The inclusion criteria were (a) studies done in primary, secondary, or tertiary hospital settings; (b) studies written in English; (c) studies published between 2006 and 2017; (c) primary qualitative, quantitative, and mixed method studies; and (d) studies focused on preceptorship models for experienced nurses who have a baccalaureate degree with more than one year of experience in the clinical area. The exclusion criteria included (a) studies focused on models of preceptorship programs for recent graduates rather than experienced nurses; (b) studies 
focused on nurses who have less than one year of experience; Several models of preceptorship programs were identified and (c) studies published before 2006, including unpublished manuscripts and dissertations. The initial search resulted in 1984 articles; however, after inclusion and exclusion criteria were applied, the final search yielded twenty articles for inclusion in this study. See results of the findings in Figure 1. in the 20 articles included in this review. These models impact preceptors, preceptees, and entire organizations. The impacts of these studies are categorized into four themes: (a) knowledge of preceptor; (b) organizational support; (c) new nurses' and preceptors' satisfaction; and (e) turnover rate, retention of nurses, and cost (see Figure 2).

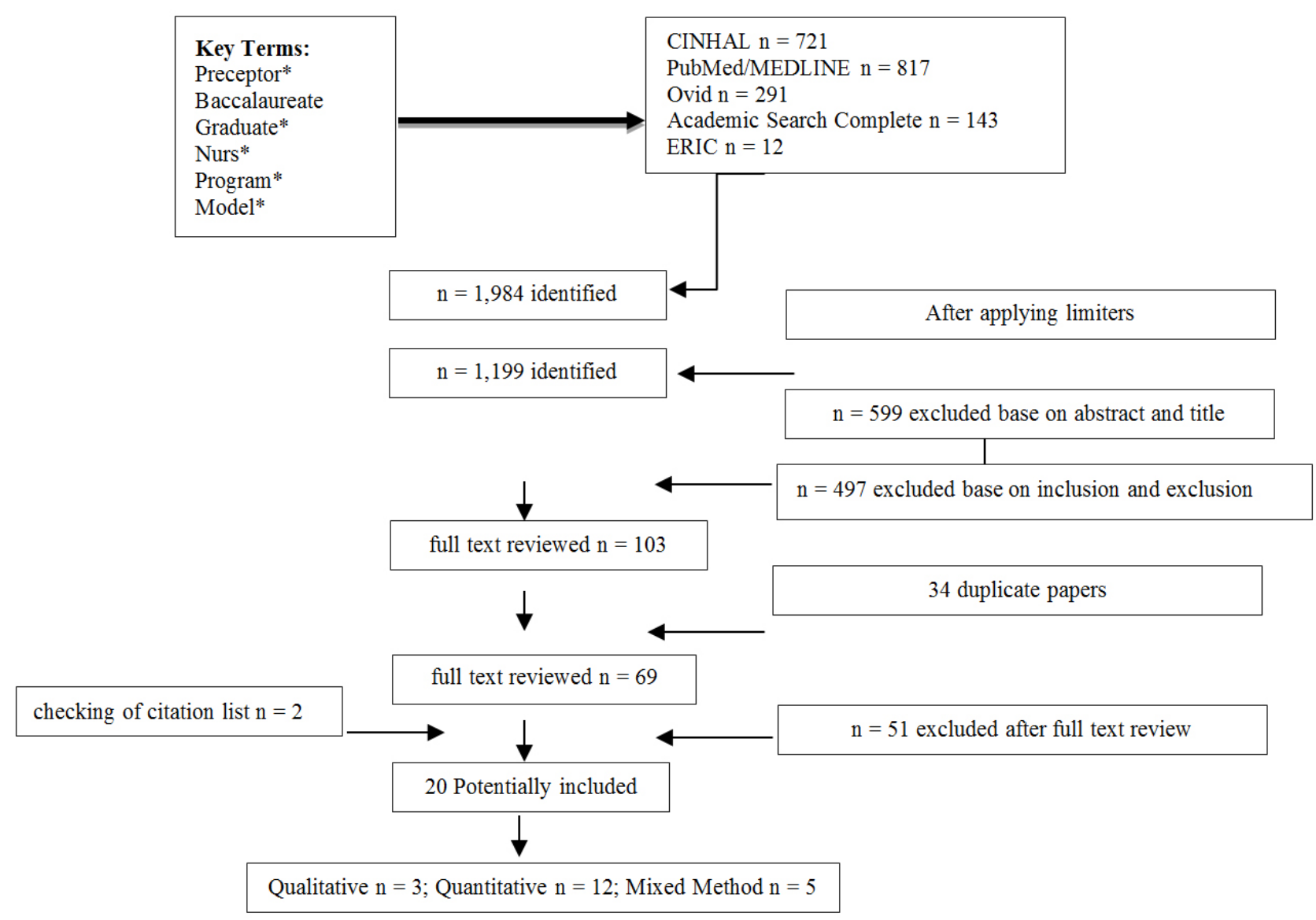

Figure 1. Search flow diagram

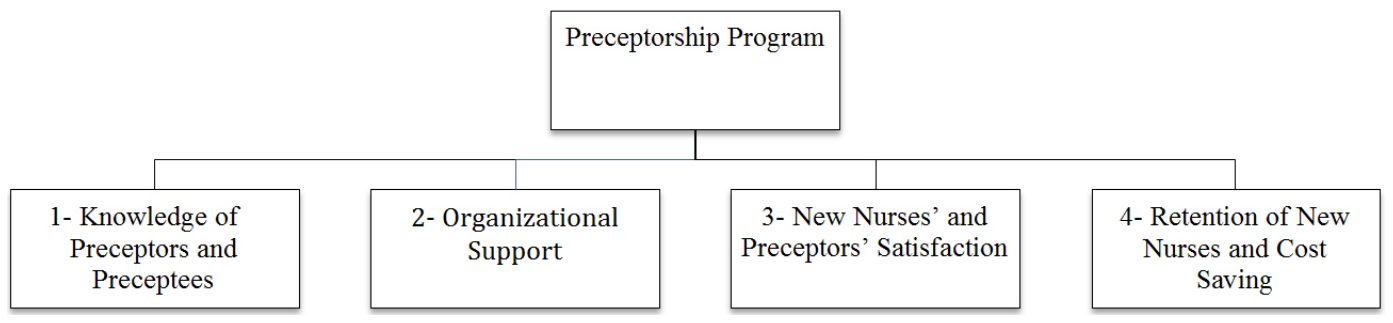

Figure 2. Identified themes

\subsection{Knowledge of preceptor}

A significant relationship has been shown between preceptorship programs and enhanced preceptor knowledge. ${ }^{[15,19,20]}$ Preceptorship programs enable preceptors to gain knowledge, skills, confidence, and positive attitudes toward preceptorship of students within work places. ${ }^{[21]}$ This will offer the best opportunity to promote safe, timely, effective, and efficient patient care. In a study conducted in hospital that utilizing preceptors $(n=31)$ in the United States, ${ }^{[3]}$ it was found that preceptorship programs were associated with improved self- 
efficiency at both immediate and 3-month post-test and increased knowledge at immediate post-test only. Self-efficacy was described by Smedley et al. ${ }^{[20]}$ as the way that nurses perceived themselves and their abilities to act in the role of preceptors.

Preceptorship programs have a significant impact on nurses' knowledge. Nurses who received preceptorship training programs increased their knowledge of teaching, knowledge of learning, and skills as a preceptor. ${ }^{[20]}$ Similarly, in a quantitative true experimental study including registered nurses $(\mathrm{N}=68)$, Karlowicz et al. ${ }^{[1]}$ found the difference between experimental group who received preceptorship programs (n $=30$ ) and control groups who did not received preceptorship programs $(\mathrm{n}=38)$ was statistically significant $(p=.000)$ after implementation of preceptor training programs. These results showed significant improvement in experimental group knowledge in clinical teaching and enhanced skills. It is hoped this improved knowledge and enhanced skill will facilitate an important opportunity for meeting expectations and achieving professional goals of preceptors in their current and future careers.

\subsection{Organizational support}

Many studies have highlighted the need for organizational support of preceptors' roles. ${ }^{[5,22,23]}$ Training and management support are required to balance preceptors' roles as clinicians and mentors. ${ }^{[20,24]}$ This may be achieved by involving numerous organizational stakeholders. According to Delfino et al., ${ }^{[25]}$ all stakeholders within an institution should support preceptorship programs in order for them to be successful and sustainable, including the chief of nursing, senior nurses, front line managers, and staff nurses at health care settings. This claim is supported by Horton et al.'s ${ }^{[26]}$ findings. These authors looked at the level of support provided by peers, managers, and educators to 714 preceptors. They found that preceptors perceived support most of the time from managers, educators, and coworkers. However, these authors also found that if these preceptors had not received any support or caring, job satisfaction of preceptees and preceptors may have decreased and intention to leave health care settings may have increased. ${ }^{[27]}$

Preceptors also require support from their hospital units and organizations to deal with workplace demands. Ongoing support of preceptors could be provided by their units through decreasing clinical work load, scheduling preceptors and preceptees on the same shift, and establishing networks with other units to support preceptors' activities. ${ }^{[24]}$ Support is needed when preceptors are dealing with struggling preceptees. ${ }^{[26]}$ Organizational support is significant in developing preceptor's roles. This support can be achieved by pro-

Published by Sciedu Press viding continuous education to preceptors through preceptor training workshops. According to Horton et al. ${ }^{[26]}$ preceptors who completed preceptor training workshops reported that the integration of knowledge learned increased their comfort level and effectiveness as preceptors, which might lead to increased satisfaction of new nurses and preceptors.

\subsection{Satisfaction of new nurses and preceptors}

New nurses' satisfaction toward their preceptors is an important feature that needs to be maintained by preceptors and organizations during new nurses' training periods. Findings have shown significant improvement in new nurses' satisfaction toward their preceptors. ${ }^{[26,27]}$ In a quantitative study conducted by $\mathrm{Hu}$ et al. ${ }^{[28]}$ to measure new nurses' satisfaction with their preceptors, they compared two groups of participants in Taiwan: one consisted of preceptors and the other of newly graduated nurses. The experimental group participants $(n=57)$ were assigned to the 10-Min Preceptorship Model (10 MP), and the control group participants $(\mathrm{n}=55)$ were assigned to preceptors following a traditional preceptorship model. There was significant improvement found by $\mathrm{Hu}$ et al. ${ }^{[28]}$ in new nurses' satisfaction toward their preceptors when they were properly trained with the $10 \mathrm{MP}$ group rather than the traditional group.

Preceptees are frustrated due to work load, lack of time to ask questions and receive feedback, and inconsistency of preceptors. ${ }^{[29]}$ Preceptees did not consistently have the same preceptor throughout preceptorship; for example, there were ten preceptors assigned to one preceptee during a preceptorship program training period. These factors lead to preceptee frustration that, in turn, affect their satisfaction level with the preceptorship experience. Therefore, organizational leads, such as head nurses, educators, and managers, must take into consideration these factors, so they may be avoided and organizational leads can provide alternative suggestions to resolve these issues.

Nurses need to feel satisfied in their role while precepting and supporting new nurses. In a quantitative study, Horton et al. ${ }^{[26]}$ reported that preceptors indicated high satisfaction levels with their role as a preceptor. Many of these preceptors stated that "it is rewarding to see someone move from novice to a competent nurse". ${ }^{23]}$ Similarly, in a qualitative study conducted by Henderson et al. ${ }^{[2]}$ with participants $(\mathrm{N}=36)$ in six focus groups to investigate how nurses perceived their training for being preceptors, they found that these preceptors were satisfied with their role after attending preceptor training. One of the preceptors stated, "My practice is now directed at educating new and junior staff where possible with greater understanding". ${ }^{[5]}$ Preceptorship programs prepare nurses to become role model; accordingly, they enhance 
and support new nurses to practice in a safe and competent manner.

\subsection{Retention of new nurses and cost saving}

Preceptorship is widely used to retain new nurses. A significant relationship has been shown between preceptorship programs and retention of new nurses. ${ }^{[3,30,31]}$ A quasiexperimental research design was used by Lee et al. ${ }^{[32]}$ to evaluate preceptorship programs effects on turnover rate and turnover cost in the United States. After conducting preceptorship programs, they found that turnover rate was reduced and turnover cost decreased by $\$ 186,102$. These claims are supported by Sandau et al. ${ }^{[29]}$ findings. They found that retention of new nurses was significantly greater than the previous year and turnover rate reduced after implementation of preceptorship programs. However, the studies included in this literature review varied; a mean reduction of $4.5 \%$ was shown by Modic et al. ${ }^{[10]}$ in turnover rate of new nurses in the last five years, and Lee et al. ${ }^{[32]}$ found a $46.5 \%$ mean reduction in turnover rate of new nurses over the previous year.

Retention of new nurses has significant impacts on organizational cost saving. Cost saving from preceptorship programs is considered an important investment for hospitals with an opportunity for retention of new nurses through preceptor support. ${ }^{[1]}$ Preceptor support offers another option for retaining new nurses and controlling cost to health care administration. ${ }^{[32]}$

Research has been recommended to measure long term outcomes, including the long-term cost reduction related to preceptorship programs to determine the effectiveness of these programs in turnover rate of new nurses. ${ }^{[27]}$ Similarly, Sandau et al. ${ }^{[29]}$ suggested that there is a need for further studies on retention of new nurses after implementing preceptorship programs.

\section{DisCUSSION}

This review of literature revealed that preceptorship programs have several impacts on preceptors' knowledge. Preceptors' knowledge is significantly increased after attending preceptorship programs. Evidence showed significant improvement and increase in nurses' knowledge after conducting preceptorship programs. ${ }^{[19]}$ Nurses gain knowledge, have an opportunity to provide feedback, evaluate new nurses in a more appropriate manner, and prepare preceptors for their role. The findings of this review are similar to the findings of Larsen et al. ${ }^{[3]}$ and Smedley et al. ${ }^{[20]}$ who noted an increase in nurses' knowledge about preceptorship after completing preceptorship programs. Nurses' knowledge is improved through continuous education and organizational support.
This literature review suggests that preceptors face many challenges while proctoring new graduate nurses. Preceptors need to know how to evaluate new nurses and give feedback and require appropriate skills and knowledge to handle conflict situations. Therefore, support should be provided to nurses to assist them to become successful in their roles and serve as a role models.

Adequate preparation of preceptors leads to successful preceptorship programs and maximized clinical experience of those preceptors. ${ }^{[9]}$

Organizational support has proven to be an important aspect that needs to be considered during preceptorship programs. Preceptorship programs need to be supported by organizational leaders. Leaders are responsible for providing immediate support for their preceptors in health care settings. Organizational leaders, including in-charge nurses, educators, and managers, need to support the preceptor role through education, support, and recognition to ensure sustainability of successful preceptorship programs. ${ }^{[11]}$ This view was supported by Heffernan et al., ${ }^{[14]}$ who highlighted that "preceptorship preparation is an ongoing process that requires preceptor support networks, follow-up with education updates and ongoing evaluation". This finding is consistent with the findings of the qualitative study by Nicol et al. ${ }^{[13]}$ and quantitative study by Hickey ${ }^{[23]}$ who concluded that preceptors need to receive organizational support and commitment. Organizational support provides an opportunity to enhance and promote new nurses' satisfaction.

Preceptorship programs have been shown to increase newly graduated nurses' satisfaction andretention. After conducting preceptorship programs, there was a significant improvement in newly graduated nurses' satisfaction toward their preceptors. ${ }^{[26]}$ This claim was supported by Salt et al.'s ${ }^{[31]}$ findings. They suggested that preceptorship programs lead to increased satisfaction of newly graduated nurses and staff retention which help in worldwide nursing shortages. When these newly graduated nurses get support and training from their preceptors through well-structured precep-torship programs, they will understand the work environment culture and consider themselves as part of their hospitals. This may improve newly graduated nurses' comfort and de-crease their stress. Ultimately, this may prevent or decrease the turnover rate of newly graduated nurses during the first year of their employment. Preceptorship programs could increase staff satisfaction and reduce turnover rate of newly graduate nurses. ${ }^{[18]}$ However, Kovner et al. ${ }^{[33]}$ reported that newly graduated nurses who are dissatisfied in the work environment are more prone to leave within the first year of practice, which might lead to increased turnover rate. Therefore, pre- 
ceptors and leaders need to offer a good atmosphere in which these newly graduated nurses feel satisfied with their work loads and their responsibilities.

Increased turnover rate of new nurses is a global concern in health care settings. The effect of preceptorship programs on turnover rates of new graduate nurses after conducting preceptorship programs were studied by Lee et al. ${ }^{[32]}$ These authors indicated that there was a 50\% de-crease in turnover rate of new nurses during the study period. This result is similar to Shermont et al.'s ${ }^{[34]}$ findings. The found that the turnover rate of new nurses decreased from $54 \%$ to $4 \%$ in 3 years after imple-menting preceptorship programs. These results indicate the importance of preceptorship programs in retaining and decreasing new nurses' turnover rates which leads to organizational cost saving.

\section{Conclusion}

Preceptorship programs have significant impacts on overall health care systems. This review assessed the effectiveness of different models of preceptorship programs which have been employed in other countries. The aim was to provide an overview of the literature that pertains to outcomes of preceptorship programs and their impacts on preceptors, preceptees, and health care settings. Most of the studies showed positive correlations between preceptorship programs and organizational outcomes, such as decreased medication errors; increased satisfaction of preceptors and preceptees; improved quality of care; and an enhanced nursing profession that leads to cost saving through staff retention. Preceptorship programs also provide an opportunity to (a) increase the number of preceptors through enhanced knowledge, (b) increase the teaching capacity of nursing programs; and (c) increase the enrollment of more new nurses. ${ }^{[34]}$ The Primary Health Care Corporation needs to consider the significance preceptorship programs have in supporting and preparing preceptors of newly graduated and hired nurses.

\section{CONFLICTS OF INTEREST DisClosure}

The authors declare that there is no conflict of interest.

\section{REFERENCES}

[1] Karlowicz KA, Ternus MP. Issues influencing psychiatric nurse retention during the first year of employment: A case analysis. J Nurs Manage. 2009 Jan; 17(1): 49-58. PMid:19166522 https: //doi.org/10.1111/j.1365-2934.2008.00850.x

[2] Gueorguieva V, Chang A, Fleming-Carroll B, et al. Working toward a competency-based preceptor development program. J Contin Edu Nurs. 2016 Jun; 47(9): 427-432. PMid:27580510 https: //doi.org/10.3928/00220124-20160817-10

[3] Larsen R, Zahner SJ. The impact of web-delivered education on preceptor role self-efficacy and knowledge in public health nurses. Public Health Nurs. 2011 July; 28(4): 349-356. PMid:21736613 https://doi.org/10.1111/j.1525-1446.2010.00933.x

[4] Kang CM, Chiu HT, Lin YK, et al. Development of a situational initiation training program for preceptors to retain new graduate nurses: Process and initial outcomes. Nur Educ Today. 2015 Nov; 37(1): 75-82. PMid:26710995

[5] Hautala K, Saylor CR, O'Leary-Kelley C. Nurses' perceptions of stress and support in the preceptor role. J Nurs Staff Deve. 2007 Mar; 23(2): 64-70. PMid:17414854 https://doi.org/10.1097/01.N ND. 0000266611.78315 .08

[6] Young J, Rogal SM. Exploring critical thinking in critical care nursing education: A pilot study. Contin Edu Nurs. 2008 Feb; 39(1): 28-33. https ://doi.org/10.3928/00220124-20080101-08

[7] Burns HK, Northcutt T. Supporting preceptors: A three-pronged approach for success. J Contin Edu Nurs. 2009 Nov; 40(11): 509-600. PMid:19904864 https://doi.org/10.3928/00220124-20091 023-08

[8] Hallin K, Danielson E. Being a personal preceptor for nursing students: Registered nurses' experiences before and after introduction of a preceptor model. J Advance Nurs, 2009 Jan; 65(1): 161-174. PMid:19032507 https://doi.org/10.1111/j.1365-2648. 20 08.04855.x

Published by Sciedu Press
[9] Zilembo M, Monterosso L. Nursing students' perceptions of desirable leadership qualities in nurse preceptors: A descriptive survey. Contemporary Nurs. 2014 Dec; 27(2): 194-206. https://doi.or $\mathrm{g} / 10.5172 /$ conu. 2008.27.2.194

[10] Modic, MB, Harris R. Masterful Precepting using the become method to enhance clinical teaching. J Nurs Dev. 2007 Jan; 3(1): 1-9.

[11] Condrey T. Implementation of a preceptor training program. J Contin Edu Nurs. 2015 Aug; 46(10): 462-469. PMid:26430866 https://doi.org/10.3928/00220124-20150918-04

[12] Yonge O, Billay D, Myrick F, et al. Preceptorship and mentorship: not merely a matter of semantics. Int J Nurs Educ Scholarsh. 2007 Feb; 4(1): 13-19. PMid:18052917 https://doi.org/10.2202/ 1548-923X.1384

[13] Nicol P, Young M. Soil training. J Nurs Staff Dev. 2007; 23(6): 298302. PMid: 18043340 https://doi.org/10.1097/01. NND .000 0300838.66728 .93

[14] Heffernan C, Herffernan, E Brosnan M, et al. Evaluating a preceptorship programme in South West Ireland: perceptions of preceptors and undergraduate students. J Nurs Manag. 2009 Jun; 17(1): 539-549. PMid:19575712 https ://doi .org/10.1111/j.1365-2834.20 $08.00935 . x$

[15] Kowalski S, Cross CL. Preliminary outcomes of a local residency programme for new graduate registered nurses. J Nurs Manage. 2010 Jan; 18(1): 96-104. PMid:20465735 https://doi .org/10.1111/ j.1365-2834.2009.01056.x

[16] Goss CR. Systematic review building a preceptor support system, J Nurs Prof Dev. 2015 Nov; 31(1): 7-14. PMid:25325297 https: //doi.org/10.1097/NND.0000000000000117

[17] Schaubhut RM, Gentry JA. Nursing preceptor workshops: partnership and collaboration between academia and practice. J Contin Edu Nurs. 2010 Apr; 41(4): 155-160. PMid:20411886 https: //doi.org/10.3928/00220124-20100326-01 
[18] Duteau J. Making a difference: the value of preceptorship programs in nursing education. J Contin Edu Nurs. 2012 Jul; 43(1): 37-43. PMid:21688761 https://doi.org/10.3928/00220124-20110 615-01

[19] Condrey T. Implementation of a preceptor training program. J Contin Edu Nurs. 2015 Aug; 46(10): 462-469. PMid:26430866 https://doi.org/10.3928/00220124-20150918-04

[20] Smedley A, Morey P, Race P. Enhancing the knowledge, attitudes, and skills of preceptors: an Australian perspective. J Contin Edu Nurs. 2010 Mar; 41(10): 451-61. PMid:20540460 https://doi. org/10.3928/00220124-20100601-08

[21] Smedley AM. Becoming and Being a Preceptor: A phenomenological study. J Contin Edu Nurs. 2008 Apr; 39(4): 242-249. https : //doi.org/10.3928/00220124-20080401-08

[22] DeCicco J. Developing a preceptorship/mentorship model for home health care nurses. J Community Health Nurs. 2008 Mar; 25(1): 15-25. PMid:18444063 https://doi.org/10.1080/07370010 701836310

[23] Hickey MT. Preceptor perceptions of new graduate nurse readiness for practice. J Nurs Staff Deve. 2009 Jan; 25(1): 35-41. PMid:19182556 https ://doi.org/10.1097/NND.0b013e3181 $94 \mathrm{~b} 5 \mathrm{bb}$

[24] Henderson A, Fox R, Malko-Nyhan K. An evaluation of preceptors' perceptions of educational preparation and organizational support for their role. J Contin Edu Nurs. 2006 May; 37(3): 130-136. PMid:18814394 https ://doi .org/10.3928/00220124-20060 301-04

[25] Delfino P, Williams JL, Wegener JM, et al. The preceptor experience: the impact of the vermont nurse internship project/partnership model on nursing orientation. J Nurs Prof Dev. 2014 Jun; (3): 122-126.

[26] Horton CD, Depaoli S, Hertach M, et al. Enhancing the effectiveness of nurse preceptors: the nurse preceptor academy. J Nurs Staff Dev. 2012; 28(4): 8-9. PMid:22821027 https ://doi.org/10.1097/ NND. Ob013e31825dfb90
[27] Chen YH, Duh YJ, Feng YF, et al. Preceptors' experiences training new graduate nurs-es: A hermeneutic phenom- enological approach. J Nurs Reserch. 2011 June; 19(1): 132-140. PMid:21586990 https ://doi.org/10.1097/JNR.0b013e31821aa155

[28] Hu YC, Chen SR, Chen IH, et al. Evaluation of work stress, turnover intention, work experience, and satisfaction with preceptors of new graduate nurses using a 10-minute preceptor model. J Contin Edu Nurs. 2015 Jan; 46(6): 261-271. PMid:26057163 https://doi.org/10.3928/00220124-20150518-02

[29] Sandau KE, Halm M. Effect of a preceptor education workshop: Part 2. qualitative results of a hospital-wide study. J Contin Edu Nurs 2010 Nov; 42(4): 172-181. PMid:21053792 https : //doi .org/10 .3928/00220124-20101101-02

[30] Jeggels JD, Traut A, Africa F. A report on the development and implementation of a preceptorship training programme for registered nurses. Curationis. 2013 Jan; 36(1): 1-6. https ://doi .org/10.4 102/curationis.v36i1.106

[31] Salt J, Cummings GG, Profetto-McGrath J. Increasing retention of new graduate nurses. J Nurs Adm. 2008 June; 38(6): 287-296. PMid:18562833 https://doi.org/10.1097/01. NNA.0000312 $788.88093 .2 \mathrm{e}$

[32] Lee TY, Tzeng WC, Lin CH, et al. Effects of a preceptorship programme on turnover rate, cost, quality, and professionals' development. J Clinic Nurs. 2009 Apr; 18(8): 1217-1225. PMid:19320789 https://doi.org/10.1111/j.1365-2702.2008.02662.x

[33] Kovner CT, Brewer CS, Fairchild S, et al. Newly licensed RNs' characteristics, work attitudes and interventions to work. Am J Nurs. 2007 Sept; 107(9): 58-70. PMid:17721152 https ://doi.org/10. 109 7/01.NAJ .0000287512.31006.66

[34] Shermont H, Krepcio D. The Impact of culture change on nurse retention. J Nurs Adm. 2006 Oct; 36(9): 407-415. PMid:16969252 https://doi.org/10.1097/00005110-200609000-00007 